\title{
Challenges and Promise for Nuclear Medicine in Africa
}

\author{
A Conversation Between Mike Sathekge and Johannes Czernin
}

$\mathbf{J}$ ohannes Czernin, MD, talked with Mike Sathekge, MBChB, MMed, PhD, a professor and head of the Nuclear Medicine Department at the University of Pretoria and Steve Biko Academic Hospital (South Africa). He has performed several first-in-humans studies in peptide-receptor radionuclide therapy and peptide radioligand therapy, as well as in ${ }^{225}$ Ac-prostate-specific membrane antigen therapy (PSMA) for prostate cancer, and has introduced these techniques in Africa. His publication and invited presentation record has earned him several key awards for research, including being rated as an internationally acclaimed researcher by the National Research Foundation and winning the award to host the Main Nuclear Medicine Research Infrastructure (NuMeRI) facility at Pelindaba in South Africa. NuMeRI will be equipped with a cyclotron, a good-manufacturing-practice-certified radiopharmacy production facility, and state-of-the-art preclinical and clinical imaging modalities. Dr. Sathekge is a fellow of the Academy of Medicine, Singapore, and is an abstract reviewer on infection imaging for the SNMMI annual meeting. He serves on the workgroup for SNMMI appropriate-use criteria on musculoskeletal infection imaging. He is one of two editors-in-chief of Seminars in Nuclear Medicine, an associate editor of the European Journal of Nuclear Medicine and Molecular Imaging, an associate editor of the World Journal of Nuclear Medicine, and an international associate editor of The Journal of Nuclear Medicine (JNM). He is the president-elect of the World Association of Radiopharmaceuticals and Molecular Therapy. He is the immediate past chair of the Medical Research Council of South Africa and immediate past president of the Colleges of Medicine of South Africa (national specialist examining body for all disciplines), as well as immediate past president of the International Society of Radiolabeled Blood Elements and past secretary general of the World Federation of Nuclear Medicine and Biology.

Dr. Czernin: You have held major leadership functions in nuclear medicine nationally and internationally, and you are currently chair of the Nuclear Medicine Department at the University of Pretoria. You grew up during apartheid, when school was not very enabling. Can you tell us about this experience and how you were able to become a leading physician/scientist?

Prof. Sathekge: I always take my inspiration from the saying that "it is better to light a candle than to curse the darkness" and from the mentorship of my mother, who was a staff nurse. My father died when I was 10 years old, and my mother had to leave nursing to go into industry to earn a better living and take care of 5 children. This was a difficult time, as this was right in the middle of apartheid. We always had to run away from the police- - whenever there was a problem, like an uprising or some altercation, the police would chase us. It didn't matter whether we participated or not. At one point I tried to skip the country. My mother found out, was very upset, and took me and my brother to a boarding school.

COPYRIGHT (C) 2021 by the Society of Nuclear Medicine and Molecular Imaging DOI: 10.2967/jnumed.121.262179
That was the end of my escape ideas. Boarding school was tough, but I was fortunate to have a great mentor: a mathematics teacher, Mr. Visser. He told me that I would be his number 1 student. I had to make sure that I didn't disappoint him, and that switched me from focusing on soccer to academics. Indeed, I was the top student for mathematics for the whole country. The education system in South Africa was such that we were denied everything that would make us better. We were not supposed to know mathematics.

Dr. Czernin: The boarding school was still completely segregated?

Prof. Sathekge: It was completely segregated. We couldn't go to White schools, and White children could not go with us. But in my particular boarding school there still were high-quality teachers. They provided good-quality education, despite what was legally prescribed by the apartheid system. In most schools, unfortunately, the learners were exposed to inferior education. If the apartheid government had kept the education system equal, that might have helped to lessen the inequities that continue to prevail in South Africa. But education for Black individuals amounted to mental genocide, if you want to call it that. A lot of people could do nothing with the type of education they had received, resulting in the many problems we still see. This is really sad.

Dr. Czernin: When you moved on to college, was there still apartheid?

Prof. Sathekge: It was still segregated. The Medical University of South Africa at that time was called MEDUNSA, and it was for Black students. But among the other universities, the University of Pretoria was the hub of apartheid. I wanted to study engineering, but my family said I should study medicine so that I could be independent and not hamstrung by the apartheid system. The decision to go to MEDUNSA was at the last minute but was a blessing because we had good and caring medical doctors who were very competent. I finished at the top of the class for the entire school. With my background in mathematics and science, I thought nuclear medicine would be interesting. I also had the privilege of receiving a scholarship for the Katholieke University of Leuven (Belgium), where I was trained in PET and applications of nuclear medicine not then available in South Africa. Being in Leuven was exciting and created lifelong friendships and 
collaborations; hence, I also did my $\mathrm{PhD}$ at Ghent University (Belgium).

Dr. Czernin: When did you get the call to Pretoria? That must have been later, when they cleaned up after the apartheid.

Prof. Sathekge: In 2002, when I was still at MEDUNSA and responsible for nuclear medicine there, the University of Pretoria called me to help them on a part-time basis. Then in 2005, I was recruited for a full-time position and have been the chair of nuclear medicine since 2005.

Dr. Czernin: Tell us a little bit about the medical system in South Africa. In the United States, we largely have a fee-forservice system. In Europe, the number of studies performed is not linked to physician salaries. So how does the system work in South Africa?

Prof. Sathekge: In the university hospital, salary is not dependent on volume. The study volume is determined by the clinical budget allocation. My role as chair is to argue for a specific amount to meet patients' needs.

Dr. Czernin: How is research funded from the bench to clinical trials?

Sathekge: We have 2 main streams of research funding: our National Research Foundation, which in the past has focused on basic science, and the Medical Research Council, which was more clinical. However, the two are now merging their roles to fund both basic and clinical research. Research is still a problem for many clinicians and also for previously disadvantaged physicians. We have to deliberately support previously disadvantaged physicians without necessarily compromising the science, thus demonstrating excellence through diversity.

Dr. Czernin: How much time for research do clinical faculty
Dr. Czernin: South Africa has not only a different history but also different demographics from other African countries. How are the medical needs of the population in South Africa different from those of other African countries? We are in nuclear medicine, which is not considered primary care, and so at times it could even be considered a luxury item. What would your key investments in African health care in different countries include?

Prof. Sathekge: These are quite loaded questions. Compared with the rest of the world, we have what we call the "quadruple burden of disease": maternal and child mortality, violence and injury, HIV and tuberculosis, and noncommunicable diseases. We have almost all of these in South Africa. The rest of the continent has less reported violence than our country. The entire continent has higher maternal and child mortality. With regard to infections, South Africa records the higher number, but I think this is a question of reporting. Other African countries have more or less the same infection rates, but these are not well documented. South Africa is doing poorly when it comes to diabetes and hypertensionwe are almost at North American levels. But cancer is really cutting across for everyone. Therefore, if one were to invest, we should prioritize human capital and infrastructure. The acute need is to first improve the hospital management systems that are dysfunctional. It is an embarrassment for the political leadership of Africa not to invest in human resources, infrastructure, and equipment. Unlike regular citizens, politicians can fly to the United States or the United Kingdom to get medical treatment, a situation that is terrible and unfair for their countries. I would also invest in education to generate capable people who will do their best to improve health care and the knowledge economy. I would invest in cancer research. Africa is a continent of young people. Thus, cancer

\section{"Continuous improvement with better patient outcomes and sustainable success."}

have?

Prof. Sathekge: Three to 4 years. But most of the time the funds dry up after 3.5 years. We recruit highly talented people who can be engaged in projects and can later help in securing research grants. But we are also involved in helping the African continent. For example, we are a designated training center to which the International Atomic Energy Agency is sending students. People from our continent come to us for training; however, when they go back, there are no positions for them because of lack of infrastructure and designated nuclear medicine posts.

Dr. Czernin: You mentioned before that Pretoria University was actually the epicenter of apartheid. How diverse are the faculty and leadership of the institution now?

Prof. Sathekge: The University of Pretoria made a concerted effort to address this issue. Undergraduates are now 55\% Black. Postgraduates are divided equally between White and Black individuals. In terms of medical staff, we still have to make important gains, because for many people of color it is difficult to stay in academia, where the culture is sometimes considered to be hostile. Thus, for the whole country we still have only $17 \%$ Black academics, whereas at the University of Pretoria we are at $29 \%$. We have to make a concerted effort to promote diversity and excellence simultaneously, and diversity has to be central when assessing senior management of universities. will become even more prevalent. There are hardly any good radiotherapy units. We need international leaders to say how diseases are best managed, including imaging in the discussion. In addition, we must avoid having guidelines that exclude imaging for developing continents such as Africa. These enable some African leaders to say, "Well, we don't need these modalities. It's a luxury to have CT, PET/CT, and other techniques." That's the wrong message.

Dr. Czernin: What about screening and vaccination programs?

Prof. Sathekge: These are getting better. All children must be vaccinated now. But we don't have a solid primary-care system or a social medicine system that makes sure that patients, both children and adults, are followed up. Social medicine is, in fact, very central to better health care. Your question is very important from my point of view, in that it emphasizes the fact that biomedicine is crucial. But we cannot ignore social medicine if we are to positively impact the lives of the people.

Dr. Czernin: In the United States, we recently experienced the peak of COVID, with an enormous number of daily infections and overflowing hospitals and intensive-care units. At least for healthcare workers, the situation is improving as they are vaccinated. What is the status of COVID right now in South Africa and other African countries? What is the vaccination supply and rollout plan for South Africa and the continent? 
Prof. Sathekge: Africa is a clear example of what can be called a syndemic rather than a pandemic. It is not only the infection part at which we should look but the constellation of noncommunicable disease that goes with it and the social element. COVID has really further exposed social inequalities.

Dr. Czernin: You are referring to differences in medical care?

Prof. Sathekge: Yes. Many people have no resources, unlike some of us with several options. It is very different when you live $50 \mathrm{~km}$ or more from the next health-care facility and have no possibilities for social distancing. Online education excludes the poorer communities, so that they are even worse off. COVID has really deepened social inequalities; therefore, we truly have a syndemic.

Dr. Czernin: Your definition of syndemic includes the disease itself and the simultaneous social contributors that synergistically make the disease outcomes worse. For example, disadvantaged groups who live in rural areas or poverty have no access to health care. Not only is the incidence of COVID higher, so is the mortality, and the social consequence are also dramatically worse.

Prof. Sathekge: In South Africa, we are much better off than the rest of the continent. At least our health-care facilities, including the laboratory system, are functional. We have around 1.5 million infected people. Our recovery rate is good, but close to 50,000 patients have died. Nevertheless, I have to qualify this, because there is also a debate about whether we are capturing mortality cases well. Especially in our poorer communities, we are seeing excess deaths not linked to COVID. As in the Western countries, our infection rate and death toll were higher during our winter. Now we are in our second wave, which was made worse by the holiday period in December. We had superspreading events, which led to a peak of 22,000 infections per day. Moreover, we have the new variant $501 \mathrm{Y}$.V2, which is $50 \%$ more transmissible than previous variants. It is difficult to know accurate statistics for the overall continent. Nigeria, for example, with around 200 million people, reports fewer infections than expected. I think this could be due to affordability and fewer tests being conducted.

Dr. Czernin: Have you started vaccination? How much of the population will you be able to vaccinate within the foreseeable future?

Prof. Sathekge: Our vaccine program will start at the end of February with 3 phases. The first will include health-care workers, the second vulnerable individuals and patients with comorbidities, and the last phase the general population. We are targeting vaccination of $67 \%$ of the population to achieve herd immunity. But I doubt that we will achieve those numbers, because of the costs and the large number of illegal immigrants. We will be receiving the AstraZeneca vaccine that is produced in India. It appears that we negotiated badly on the cost, hence we are initially expected to receive around 1.5 million doses. There is some confusion with the rollout because of the vaccine's apparent lower efficacy against
501Y.V2. There are also concerns about the fact that only the government can procure vaccines and then sell to private entities and distribute to university hospitals. So, vaccination management is really not going as desired.

Dr. Czernin: Mike, we are coming to the end of this discussion. What would you like to be the take-home message for our readers? How can professional societies and also our journal contribute to health care on the African continent?

Prof. Sathekge: $J N M$ is leading globally. It is an important voice, and when it speaks, the World Health Organization and governments listen. It would be helpful if $J N M$ could provide position statements and guidelines for best disease management, such as the appropriate-use criteria. Collaborations are the way to go, but they should be done as true partnerships. For our field it would be important to dispel the myth that nuclear medicine is a luxury. Take theranostics, for example: prostate cancer therapy must not only happen in the United States, Australia, Asia, and Europe. African leaders need to understand the importance of these new approaches. Being a poor country doesn't have to mean poor health care. We need to collaborate on research and development. People such as you must go to see Tanzania, for example, to see what is happening so that you can do research that will focus on their needs and interests. A case in point: many of our prostate cancer patients present to us very late, with aggressive disease. Many do not qualify for chemotherapy or radiation therapy. Therefore, PSMA-targeted radioligand therapy would be very beneficial in Africa. These are the things we have to understand when discussing sequencing priorities and decisions. For instance, our ongoing work on ${ }^{225}$ Ac-PSMA is demonstrating improvement in overall survival and quality of life for prostate cancer patients. Rather than being a luxury item, theranostics can be of benefit to this continent, and it would be of benefit because of the manner in which the disease presents: aggressive, late, and compounded by a lack of resources for standard of care.

Dr. Czernin: You're making the argument that recent developments, such as theranostics but also all advanced diagnostics, must not be considered as luxuries but as what should be the standard of care in South Africa and the African continent. The best care should be the aim for the African continent, as it is for the rest of the world.

Prof. Sathekge: We must continually demonstrate that innovation and excellence are important and should be accessible to everyone, not as luxuries. In the end, it all comes down to loving and caring for each other as people of the world. There is an African proverb that says, "Motho Ke Motho Ka Batho," meaning "We are people, because of each other."

Dr. Czernin: Thank you, Mike, for this inspiriting discussion. Our readers and the JNM team are grateful for your willingness to talk to us. 